\title{
Particulate matter and lung function growth in children: a 3-yr follow-up study in Austrian schoolchildren
}

\author{
F. Horak Jr*, M. Studnicka\#, C. Gartner*, J.D. Spengler", E. Tauber*, R. Urbanek*, A. Veiter*, \\ T. Frischer*
}

\begin{abstract}
Particulate matter and lung function growth in children: a 3-yr follow-up study in Austrian schoolchildren. F. Horak Jr, M. Studnicka, C. Gartner, J.D. Spengler, E. Tauber, R. Urbanek, A. Veiter, T. Frischer. (C) ERS Journals Ltd 2002.

ABSTRACT: The effects of particulate matter $<10 \mu \mathrm{m}$ in diameter (PM10) and other air pollutants on lung function were assessed in 975 schoolchildren, from eight communities in Lower Austria between 1994-1997. In each community, air pollution data were collected. Spirometry was performed twice a year. PM10 concentration (mean concentration between two subsequent lung-function measures in spring and autumn (summer interval) or between autumn and spring (winter interval)) showed a mean value of $17.36 \mu \mathrm{g} \cdot \mathrm{m}^{-3}$ in the summer interval and $21.03 \mu \mathrm{g} \cdot \mathrm{m}^{-3}$ in the winter interval. A slower increase in the forced expiratory volume in one second (FEV1) and midexpiratory flow between 25 and 75\% of the forced vital capacity (MEF25-75) with age in children exposed to higher summer PM10 was observed in the 3-yr study period. After adjusting for potential confounders (sex, atopy, passive smoking, initial height, height difference, site, initial lung function) an increase of summer PM10 by $10 \mu \mathrm{g} \cdot \mathrm{m}^{-3}$ was associated with a decrease in $\mathrm{FEV} 1$ growth of $84 \mathrm{~mL} \cdot \mathrm{yr}^{-1}$ and $329 \mathrm{~mL} \cdot \mathrm{s}^{-1} \cdot \mathrm{yr}^{-1}$ for MEF25-75. Nitrogen dioxide and ozone also showed a negative effect on lung-function growth, confirming previous work.

The authors concluded that long-term exposure to particulate matter $<10 \mu \mathrm{m}$ in diameter had a significant negative effect on lung-function proxy for the development of large (forced expiratory volume in one second) and small (midexpiratory flow between 25 and $75 \%$ of the forced vital capacity) airways, respectively, with strong evidence for a further effect of ozone and nitrogen dioxide on the development of forced vital capacity and forced expiratory volume in one second.

Eur Respir J 2002; 19: 838-845.
\end{abstract}

\author{
*University Children's Hospital, Vienna, \\ Austria. "Dept of Lung Disease, St \\ Johann Hospital, Salzburg, Austria. \\ "Harvard School of Public Health, \\ Boston, MA, USA.
}

Correspondence: T. Frischer

University Children's Hospital Vienna Waehringerguertel 18-20

1090 Vienna

Austria

Fax: 431404003189

E-mail: thomas.frischer@akh-wien.ac.at

Keywords: Air pollution

cohort study

lung-function growth

particulate matter

schoolchildren

Received: April 142001

Accepted after revision December 14 2001
In recent years numerous studies have observed associations between ambient particulate matter and respiratory health. Effects of particulate air pollution on respiratory symptoms [1-8], hospitalization for respiratory and cardiovascular disease $[9,10]$, asthma attacks [11-13] asthma-medication use [1, 14], lung function [1-3, 7, 15-17] and mortality [18, 19] have been shown. Several studies observed short-term associations between particulate matter and lung function. Hoek et al. [2] found in a study on Dutch children that an increase of particulate matter $<10 \mu \mathrm{m}$ in diameter (PM10) by $100 \mu \mathrm{g} \cdot \mathrm{m}^{-3}$, on the same day, was associated with a decrease in different lungfunction parameters (forced vital capacity (FVC), forced expiratory volume in one second (FEV1)) by $\sim 2.5 \%$. Investigations of symptomatic and asymptomatic children in the USA [20] showed a decrease in the peak expiratory flow by $1.8 \%$ and $1.3 \%$ respectively, associated with a $150 \mu \mathrm{g} \cdot \mathrm{m}^{-3}$ increase in the concurrent days' PM10. A summer-camp study in the Austrian Alps [21] suggested a cumulative negative short-term effect of acid aerosols and PM10 on FEV1. So far, a susceptible subpopulation has not been identified. A study in the European Union found no consistent association between PM10 and lung function in a sample of children with chronic respiratory symptoms [22]. The six-cities study [23] that observed cross-sectionally the long-term effect of particulates, revealed no association with children's lung function. Conversely, the 24-cities study [24] showed a strong influence of annual means of PM10, ozone $\left(\mathrm{O}_{3}\right)$ and particle strong acidity on the lung function of elementary-school children. A difference of $17.3 \mu \mathrm{g} \cdot \mathrm{m}^{-3}$ in annual mean PM10 was associated with a $2.4 \%(95 \%$ confidence interval (CI) $0.5-4.3)$ decrement in adjusted FVC and a $2.1 \%$ (95\% CI $0.1-4.0)$ decrement in adjusted FEV1.

Fewer studies are available that investigated the influence of air pollution on lung-function growth. A recently published cohort study from LA (USA) [25] followed schoolchildren over a period of $4 \mathrm{yrs}$. The investigators observed a significant effect of measures of particulate matter (PM10, particulate matter $<2.5 \mu \mathrm{m}$ in diameter (PM2.5), PM10-PM2.5) on lungfunction growth at rather high levels of air pollution $\left(51.5 \mu \mathrm{g} \cdot \mathrm{m}^{-3}\right.$ PM10 (annual average) differences between the least and the most polluted community).

Recently published analyses of the first 2 yrs 
(1994-1996) of the Austrian Lung and Air Study showed small but consistent decrements in lungfunction growth associated with ambient $\mathrm{O}_{3}$ [26]. The aim of the present longitudinal analysis of a prospective cohort study was to evaluate the effect of PM10 on the lung-function growth of schoolchildren at ambient levels of air pollution. As data for PM10 from autumn 1994 to autumn 1997 are now available, the results from one additional year are reported, in contrast to previous analyses by the authors [26].

\section{Materials and methods}

\section{Study sites}

Eight study sites were selected in the region of Lower Austria on the basis of the 1991-1993 annual average of $\mathrm{O}_{3}$, to represent a broad range of concentrations for air pollutants as described previously [26]. In each region a fixed monitor station run by the governmental air-pollution surveillance agency of Lower Austria must have been installed. Sites with major industry in the vicinity were excluded. One site in Styria (Pöllau) which was evaluated in former analyses was not considered in the present analysis because no PM10 data were available. Five regions (St.Valentin, Heidenreichstein, Gänserndorf, Mistelbach, Bruck) were rural, with a population size between 4,000- 10,000. One rural region in the South of Lower Austria (Wiesmath) consisted of four small villages with $\sim 1,000$ inhabitants each and one elementary school per village. In two towns the population was $\sim 20,000$. The regions were situated 161-738 $\mathrm{m}$ above sea level. Schools were assigned in each region from local school authorities (table 1).

\section{Study population}

In the selected schools, children in grades 2-3 were recruited in the beginning of the study period. Lung function was assessed between September 1994September 1997, twice a year. Compared to initial evaluations of the study years 1994-1996 [26], data for an additional year (1997) are reported for the present analyses. Each child was examined in spring (MarchJune) and early autumn (September-November) with a maximum of seven repeated examinations throughout the study period. A protocol complying with American Thoracic Society (ATS) standards was used as described previously [26]. Once a year parents were asked to complete a questionnaire including questions on their child's respiratory symptoms in the last 12 months as well as socioeconomic factors. The core questions on asthma and allergy of the International Study on Childhood Asthma and Allergy [27] were incorporated into the questionnaire [7]. Exposure to environmental tobacco smoke (ETS) was defined as positive, when at least 1 cigarette $\cdot d a y^{-1}$ was smoked at the child's home. A skin-prick test was performed in spring 1994 and in autumn 1997 using seven common aeroallergens (cat, dog, birch, hazel, grass, house dust mite (Dermatophagoides pteronyssinus and D. farinae);

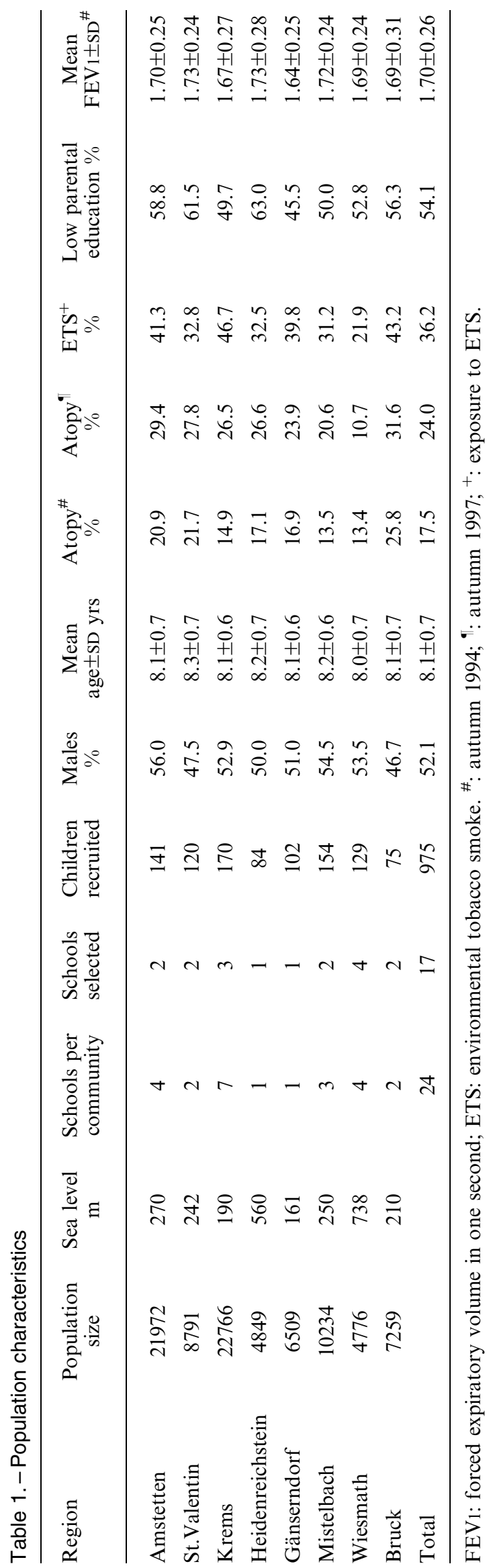


Allergologisk Laboratories A/S, Horshol, Denmark) as well as histamine $\left(10 \mathrm{mg} \cdot \mathrm{mL}^{-1}\right)$ and $\mathrm{NaCl}$ as respective positive and negative controls. Atopy was defined as a skin weal of $\geqslant 2 \mathrm{~mm}$ in diameter to any allergen and one-half the size of the histamine weal. Parents were asked to give informed written consent for their child's participation in the study. The study protocol was approved by the Ethics Committee of the University of Vienna.

\section{Ambient monitoring}

At the fixed-monitor stations continuous monitoring of temperature, $\mathrm{O}_{3}$, sulphur dioxide $\left(\mathrm{SO}_{2}\right)$ and nitrogen dioxide $\left(\mathrm{NO}_{2}\right)$ was conducted by the governmental air-pollution surveillance agency of Lower Austria. The stations were located in the immediate vicinity of the elementary schools. Places close to frequented roads or major industry were avoided. $\mathrm{O}_{3}$ was measured using chemoluminiscence analysers (ML8810; Monitor Laboratories, San Diego, CA, USA) according to Environmental Protection Agency guidelines. $\mathrm{NO}_{2}$ was measured by nitric oxide $(\mathrm{NO} /$ NOx) analysers (ML-8840; Monitor Laboratories). PM10 measurements were performed solely for the purpose of the study using Harvard Impactors under the supervision of the Dept of Environmental Health of the Harvard School of Public Health, Boston (MA, USA). The impactor system was designed to sample particles with a 50\% cut-off aerodynamic diameter of $10 \mu \mathrm{m}$. The Teflon filters used were preweighted in a temperature- and humidity-controlled environment. Air was sucked through the system with a flow of $\sim 4 \mathrm{~L} \cdot \mathrm{min}^{-1}$. Air volume was measured using a calibrated gas meter. Filters were changed at 2-weekly intervals by local authorities and reweighted at Harvard. PM10 concentration was calculated using the formula:

$$
\mathrm{PM}_{10}\left(\mu \mathrm{g} \cdot \mathrm{m}^{-3}\right)=\Delta \mathrm{F} 2 \mathrm{~F} 1 / \Delta \mathrm{G} 2 \mathrm{G} 1
$$

Where: F1: filter weight before measurement; F2: filter weight after measurement; G1: gas-meter volume at the beginning of the measurement; G2: gas-meter volume at the end of the measurement. PM10 data were available from September 1994-November 1997. Once a year, all of the equipment and technical performance was audited by a scientific engineer of the Harvard School of Public Health.

\section{Statistical analyses}

Calculations of the impact of particulate matter on lung-function growth were performed in different steps. In step 1 , the interval of lung-function growth between two subsequent measurements was calculated. Lung-function growth was calculated for each child separately. The difference of each lung-function parameter (FVC, FEV1, midexpiratory flow between 25 and $75 \%$ of the forced vital capacity (MEF25-75)) between two subsequent surveys was divided by the days between the two surveys. The results are presented as "difference per day" (dpd) for each parameter measured.

In step 2, the preceding interval exposure was calculated for each pollutant. The interval of air pollution between lung-function measurements in spring and autumn was determined as summer air pollution, the interval between fall and spring as winter air pollution.

In step 3, generalized estimating equations (GEE) [28] were used to account for the "repeated measurement character" of the data structure. A nonstationary M-dependent correlation structure was used in the standard models. Adjustment was provided for potential confounders (sex, atopy, ETS, baseline lung function, first height, height difference, site). To allow for different slopes for pollution parameters in winter and summer, a separate pollution parameter was introduced for the respective seasonal period.

In step 4, two-pollutant models were calculated (table 2) to account for concomitant effects of PM10 and the other pollutants.

In the last step, sensitivity analyses were performed. The standard PM10 model was recalculated using an unspecified correlation structure. Furthermore, stepby-step, parental education and presence of wheezing or rales at physical examination were introduced as new covariates. Stratified analyses were performed which included asthmatics and nonasthmatics as well as children exposed to ETS only and those not exposed. The last analysis was stratified to children who had been at home for the whole summer period.

\section{Results}

\section{Population}

At the beginning of the study 975 children were recruited. Participation by site ranged from 92.2$96.3 \%$. Major population characteristics are presented in table 1. Atopy ranged from $13.4-25.8 \%$ in 1994 , and from $10.7-31.6 \%$ in 1997 , being the lowest in Wiesmath and the highest in Bruck in both surveys. An average of $36.2 \%$ of the children were exposed to ETS. A total $80.6 \%$ of the children performed all six lung-function tests, $11.2 \%$ performed five tests and $8.2 \%$ less than five tests.

\section{Air-pollution data}

The seasonal variation of air pollutants is shown in figure 1. Data points show the seasonal mean, corresponding to the mean ambient exposure between two surveys (e.g. winter 1994: PM10 mean concentration between lung-function measurements in autumn 1994 and spring 1995). As expected $\mathrm{O}_{3}$ was lower in the winter interval than in summer throughout the study period. The PM10 profile showed higher levels in the winter interval (mean \pm SD: $21.0 \pm 4.8 \mu \mathrm{g} \cdot \mathrm{m}^{-3}$ ) and lower levels in summer $\left(17.4 \pm 2.8 \mu \mathrm{g} \cdot \mathrm{m}^{-3}\right)$. This winter/ summer difference could also be observed for $\mathrm{SO}_{2}$ (winter mean: $16.8 \mu \mathrm{g} \cdot \mathrm{m}^{-3}$, summer mean: $6.9 \mu \mathrm{g} \cdot \mathrm{m}^{-3}$ ), and $\mathrm{NO}_{2}$ (winter mean: 11.5 parts per billion (ppb), 
Table 2. - Association of long-term seasonal mean concentration of air pollutants with growth in lung function: two pollutant models

\begin{tabular}{|c|c|c|c|c|c|c|}
\hline \multirow[t]{2}{*}{ Model $^{\#}$} & \multicolumn{2}{|c|}{ FVC dpd } & \multicolumn{2}{|c|}{$\mathrm{FEV}_{1} \mathrm{dpd}^{+}$} & \multicolumn{2}{|c|}{$\mathrm{MEF} 25-75 \mathrm{dpd}^{\S}$} \\
\hline & $\beta$ & p-value & $\beta$ & p-value & $\beta$ & p-value \\
\hline \multicolumn{7}{|l|}{$\mathrm{PM}_{10}+\mathrm{O}_{3}$} \\
\hline Summer & 0.001 & 0.911 & -0.022 & 0.008 & -0.087 & 0.000 \\
\hline Winter & 0.010 & 0.019 & 0.004 & 0.338 & -0.008 & 0.434 \\
\hline \multicolumn{7}{|l|}{$\mathrm{PM}_{10}+\mathrm{NO}_{2}$} \\
\hline Summer & -0.018 & 0.056 & -0.038 & 0.000 & -0.102 & 0.000 \\
\hline Winter & 0.015 & 0.000 & 0.011 & 0.005 & 0.005 & 0.610 \\
\hline \multicolumn{7}{|l|}{$\mathrm{PM} 10+\mathrm{SO}_{2}$} \\
\hline Summer & 0.005 & 0.575 & -0.022 & 0.010 & -0.095 & 0.000 \\
\hline Winter & 0.004 & 0.492 & -0.005 & 0.358 & -0.011 & 0.474 \\
\hline \multicolumn{7}{|c|}{ PM10+temperature } \\
\hline Summer & -0.007 & 0.417 & -0.034 & 0.000 & -0.112 & 0.000 \\
\hline Winter & -0.003 & 0.599 & -0.011 & 0.016 & -0.013 & 0.295 \\
\hline \multicolumn{7}{|l|}{$\mathrm{O}_{3}+\mathrm{PM} 10$} \\
\hline Summer & -0.015 & 0.000 & -0.020 & 0.000 & -0.009 & 0.406 \\
\hline Winter & -0.010 & 0.089 & -0.012 & 0.036 & -0.009 & 0.548 \\
\hline \multicolumn{7}{|l|}{$\mathrm{NO}_{2}+\mathrm{PM} 10$} \\
\hline Summer & 0.005 & 0.515 & 0.000 & 0.973 & -0.013 & 0.447 \\
\hline Winter & -0.034 & 0.000 & -0.037 & 0.000 & -0.036 & 0.021 \\
\hline \multicolumn{7}{|l|}{$\mathrm{SO}_{2}+\mathrm{PM} 10$} \\
\hline Summer & 0.008 & 0.395 & 0.010 & 0.271 & 0.037 & 0.086 \\
\hline Winter & 0.004 & 0.225 & 0.007 & 0.025 & 0.007 & 0.429 \\
\hline
\end{tabular}

FVC: forced vital capacity; FEV1: forced expiratory volume in one second; MEF25-75: midexpiratory flow between 25 and $75 \%$ of the forced vital capacity; PM10: particulate matter $<10 \mu \mathrm{m}$ in diameter; $\mathrm{O}_{3}$ : ozone; $\mathrm{NO}_{2}$ : nitrogen dioxide; $\mathrm{SO}_{2}$ : sulphur dioxide. The model was adjusted for sex, atopy, passive smoking, height 1994, height difference, site, lung function 1994. ": change in FVC mL$\cdot$ day $^{-1}$; ${ }^{+}$: change in FEV1 mL $\cdot$ day $^{-1}$; ${ }^{\S}$ : change in MEF $25-75 \mathrm{~mL} \cdot \mathrm{s}^{-1} \cdot$ day $^{-1}$; ${ }^{\#}: \beta$ is calculated for the slope of the first air pollutant shown, adjusted for the second pollutant.

summer mean: $6.7 \mathrm{ppb}$ ) which were well below the National Ambient Air Quality Standard (NAAQS).

Figure 2 shows the PM10 profile for each site throughout the study period. PM10 concentrations ranged from 10.6 (Wiesmath, winter 1994) to $30.4 \mu \mathrm{g} \cdot \mathrm{m}^{-3}$ (Krems, winter 1995). The highest PM10 concentration was found in winter 1995 in all study regions (mean: $24.5 \mu \mathrm{g} \cdot \mathrm{m}^{-3}$ ).

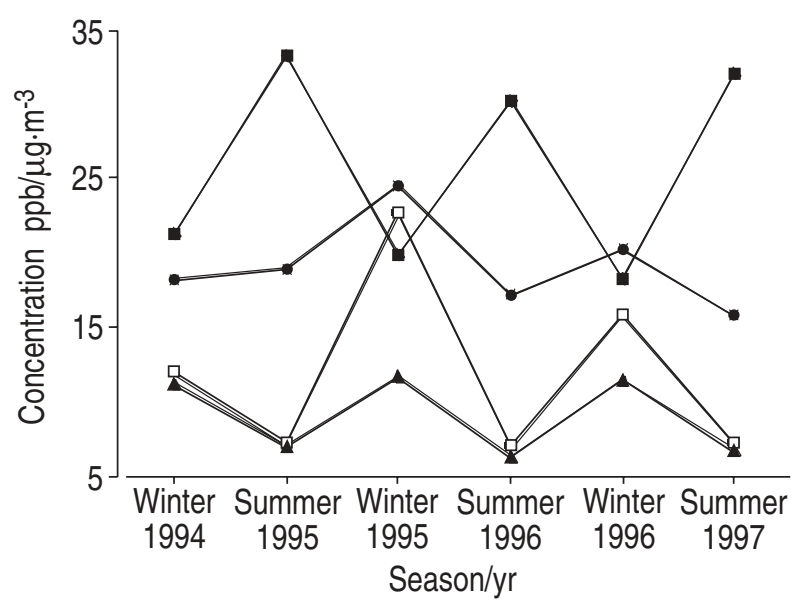

Fig. 1.-Seasonal air pollution (winter: interval between lungfunction testing in autumn and spring; summer: interval between lung-function testing in spring and autumn). $\mathbf{a}$ : ozone (parts per billion (ppb)); $\square$ : sulphur dioxide $\left(\mu \mathrm{g} \cdot \mathrm{m}^{-3}\right) ; \boldsymbol{\Delta}$ : nitrogen dioxide (ppb); : particulate matter $<10 \mu \mathrm{m}$ in diameter $\left(\mu \mathrm{g} \cdot \mathrm{m}^{-3}\right)$.
Correlation of air-pollution parameters in winter and summer (table 3 ) revealed a moderate positive correlation of PM10 with $\mathrm{SO}_{2}$ and $\mathrm{NO}_{2}$ as well as a negative correlation between $\mathrm{PM} 10$ and $\mathrm{O}_{3}$. A weak negative correlation of PM10 with temperature in winter changed to a moderate positive correlation in summer. The strongest negative correlation was found for $\mathrm{O}_{3}$ and $\mathrm{NO}_{2}$, irrespective of season.

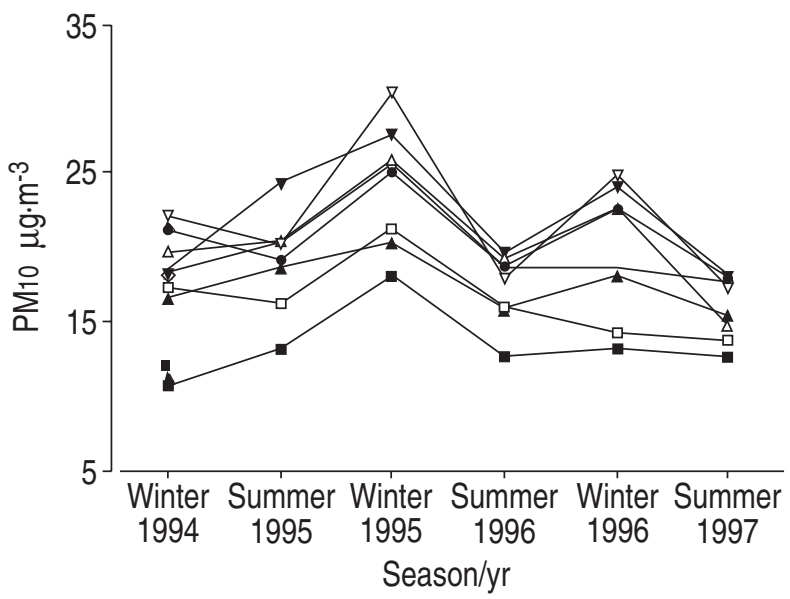

Fig. 2.-Seasonal particulate matter $<10 \mu \mathrm{m}$ in diameter (PM10) concentration per city (winter: interval between lung-function testing in autumn and spring; summer: interval between lungfunction testing in spring and autumn). $\square$ : Wiesmath; $\square$ : Heidenreichstein; $\boldsymbol{\Delta}$ : St Valentin; $\bigcirc$ : Amstetten; $\triangle$ : Mistelbach; $\nabla$ : Krems; $\nabla$ : Gänserndorf; $\diamond:$ Bruck. 
Table 3. - Correlation coefficients for the mean long-term seasonal (summer and winter) concentration of exposure variables 1994-1997

\begin{tabular}{lrrrr}
\hline & Temperature & $\mathrm{NO}_{2}$ & $\mathrm{SO}_{2}$ & $\mathrm{O}_{3}$ \\
\hline Winter & & & & \\
$\quad \mathrm{PM} 10$ & -0.106 & 0.595 & 0.520 & -0.581 \\
$\mathrm{O}_{3}$ & -0.345 & -0.839 & 0.146 & \\
$\mathrm{SO}_{2}$ & -0.519 & -0.129 & & \\
$\mathrm{NO}_{2}$ & 0.388 & & & \\
Summer $^{*}$ & & & & -0.429 \\
$\quad \mathrm{PM}_{10}$ & 0.607 & 0.412 & 0.335 & -0.625 \\
$\mathrm{O}_{3}$ & -0.428 & -0.625 & -0.204 & \\
$\mathrm{SO}_{2}$ & 0.414 & -0.144 & & \\
$\mathrm{NO}_{2}$ & 0.383 & & & \\
\hline
\end{tabular}

$\mathrm{NO}_{2}$ : nitrogen dioxide; $\mathrm{O}_{3}$ : ozone; $\mathrm{SO}_{2}$ : sulphur dioxide; PM10: particulate matter $<10 \mu \mathrm{m}$ in diameter. ${ }^{\#}$ : mean between lung-function tests in autumn and spring 1994 1997; : mean between lung-function tests in spring and autumn 1994-1997.

\section{Lung-function measurement}

Of all the children $91.3-98.3 \%$ were able to provide acceptable lung-function tests in the respective year. The loss to follow-up was $11.8 \%$ throughout the study period. Lung-function growth showed a linear slope with no growth burst (FVC dpd: $0.66 \pm 0.29 \mathrm{~mL}, \mathrm{FEV} 1$ dpd: $0.53 \pm 0.260 \mathrm{~mL}$ ). Furthermore, no difference between lung-function growth and the place of residence was seen (data not shown).

\section{Development of lung function and air pollution}

A total of 860 children were included in the GEE analyses.

Forced vital capacity. Changes in FVC, a surrogate for lung growth, were primarily influenced by $\mathrm{O}_{3}$ and $\mathrm{NO}_{2}$. $\mathrm{O}_{3}$ showed a negative relation to $\mathrm{FVC}$ dpd in winter $(\beta=-0.015 ; p=0.0001)$ and summer $(\beta=-0.014 ; p=0.007)$ even when PM10 was introduced into a two-pollutant model. Winter $\mathrm{NO}_{2}$ was also negatively associated with FVC growth $(\beta=-0.022 ; p=0.001)$. The positive relationship between the winter PM10 and FVC was obviously confounded by temperature as it lost significance and changed its direction when temperature was included in the model. Summer PM10 did not affect FVC growth.

Forced expiratory volume in one second. The development of FEV1, a proxy for large airways' growth, showed associations with all air-pollutant parameters. Summer PM10 was negatively and significantly related to FEV1 dpd. A change of $10 \mu \mathrm{g} \cdot \mathrm{m}^{-3}$ PM10 was associated with a decrease of $0.23 \mathrm{~mL} \cdot \mathrm{day}^{-1}$ FEV1. This effect remained significant even when $\mathrm{O}_{3}$, $\mathrm{NO}_{2}, \mathrm{SO}_{2}$ or temperature were introduced into twopollutant models. A significant negative effect of winter PM10 on FEV1 was revealed when temperature was added into the model $(\beta=-0.011 ; \mathrm{p}=0.016)$. Furthermore a negative association between winter $\mathrm{NO}_{2}$ and FEV1 was observed, that stayed significant even when PM10 was introduced into the model. Whereas winter $\mathrm{SO}_{2}$ showed a small positive effect on FEV1 dpd, $\mathrm{O}_{3}$ was negatively associated with the growth of FEV1. This effect slightly lost significance in winter, when PM10 was introduced into the model.

Midexpiratory flow between 25 and $75 \%$ of the forced vital capacity. MEF25-75 was measured to reflect the growth of small airways. Significantly negative associations could be found with summer PM10. This effect remained stable when the other air pollutants were accounted for in the two-pollutant models. A negative relationship of MEF25-75 to $\mathrm{NO}_{2}$ was weakened when PM10 was introduced into the model. $\mathrm{SO}_{2}$ showed no influence on the development of MEF25-75. The negative effect estimate of winter ozone decreased in size and significance after accounting for PM10.

\section{Sensitivity analyses}

Recalculation of the standard PM10 model with a different correlation structure (unspecified instead of nonstationary M-dependent correlation structure) revealed no significant change to the prior model. As shown in table 4 , according to PM10, the $\beta$ given for FVC dpd in the standard model was $0.001 \quad(p=0.938)$ for the summer period and $0.008(\mathrm{p}=0.042)$ for the winter period. Introducing unspecified correlation structure the $\beta$ was $0.004(p=0.636)$ for the summer period and $0.011(\mathrm{p}=0.002)$ for the winter period. When parental education and auscultatory status of the children was accounted for in the standard model the effect estimate and the p-value (data not shown) did not change significantly. Restricting the calculations to nonasthmatic children revealed a beta of $-0.003(p=0.710)$ for the summer and $0.009(p=0.030)$ for the winter period. A stratification to nonasthmatic children was not possible due to the small number of observations (data not shown). While calculations restricted to children not exposed to ETS did not significantly change the effect estimate (summer: $\beta=0.014, \quad p=0.154$; winter: $\beta=0.012, \quad p=0.0018)$, a marginal significant negative effect was revealed in the summer period for children exposed to ETS (summer: $\quad \beta=0.022, \quad p=0.088$; winter: $\beta=0.003$, $\mathrm{p}=0.656$ ). Taking into account only children who stayed at home the whole summer period had no influence on the results (data not shown).

\section{Discussion}

In a 3-yr prospective cohort study the authors studied the impact of air pollution on the development of lung function in 975 schoolchildren of eight regions in Lower Austria. Significant effects of $\mathrm{NO}_{2}$ and $\mathrm{O}_{3}$ on the development of lung volume, as estimated by FVC growth, and large airways (FEV1) as well as an effect of summer PM10 on the development of the large and small airways (estimated by FEV1 and MEF25-75) were observed.

Previously published evaluations [26] were based on a dataset from 1994-1996. At this time PM10 was 
Table 4.-Association of long-term seasonal mean concentration of air pollutants with growth in lung function: singlepollutant models

\begin{tabular}{|c|c|c|c|c|c|c|c|}
\hline \multirow[t]{2}{*}{ Model } & \multirow[t]{2}{*}{ Mean (range) } & \multicolumn{2}{|c|}{$\mathrm{FVC} \mathrm{dpd}^{\#}$} & \multicolumn{2}{|c|}{ FEV1 dpd } & \multicolumn{2}{|c|}{ MEF25-75 dpd ${ }^{+}$} \\
\hline & & $\beta$ & p-value & $\beta$ & p-value & $\beta$ & p-value \\
\hline \multicolumn{8}{|c|}{$\mathrm{PM}_{10} \mu \mathrm{g} \cdot \mathrm{m}^{-3}$} \\
\hline Summer & $17.4(11.7-28.9)$ & 0.001 & 0.938 & -0.023 & 0.003 & -0.090 & 0.000 \\
\hline Winter & $21.0(9.4-30.5)$ & 0.008 & 0.042 & 0.001 & 0.885 & -0.008 & 0.395 \\
\hline \multicolumn{8}{|l|}{$\mathrm{NO}_{2} \mathrm{ppb}$} \\
\hline Summer & $6.7(1.1-15.0)$ & -0.000 & 0.992 & -0.010 & 0.114 & -0.041 & 0.008 \\
\hline Winter & $11.5(4.1-18.2)$ & -0.022 & 0.001 & -0.026 & 0.000 & -0.025 & 0.090 \\
\hline \multicolumn{8}{|l|}{$\mathrm{SO}_{2} \mu \mathrm{g} \cdot \mathrm{m}^{-3}$} \\
\hline Summer & $6.9(3.1-11.7)$ & 0.009 & 0.336 & 0.005 & 0.576 & 0.015 & 0.483 \\
\hline Winter & $16.8(7.5-37.4)$ & 0.006 & 0.009 & 0.005 & 0.013 & 0.003 & 0.637 \\
\hline \multicolumn{8}{|l|}{$\mathrm{O}_{3} \mathrm{ppb}$} \\
\hline Summer & $31.8(18.7-49.3)$ & -0.015 & 0.001 & -0.021 & 0.000 & -0.013 & 0.217 \\
\hline Winter & $19.8(12.7-35.9)$ & -0.014 & 0.007 & -0.020 & 0.000 & -0.032 & 0.012 \\
\hline
\end{tabular}

MEF25-75: midexpiratory flow between 25 and $75 \%$ of the forced vital capacity; PM10: particulate matter $<10 \mu$ m in diameter; $\mathrm{NO}_{2}$ : nitrogen dioxide; $\mathrm{SO}_{2}$ : sulphur dioxide; $\mathrm{O}_{3}$ : ozone; FVC: forced vital capacity; FEV1: forced expiratory volume in one second. Model adjusted for sex, atopy, passive smoking, height 1994, height difference, site, lung function 1994. "\#: change in FVC $\mathrm{mL} \cdot \mathrm{day}^{-1}$; : change in FEV $1 \mathrm{~mL} \cdot \mathrm{day}^{-1}$; ${ }^{+}$: change in MEF25-75 $\mathrm{mL} \cdot \mathrm{s}^{-1} \cdot \mathrm{day}^{-1}$.

measured over a period of 2 yrs from autumn 1994 to autumn 1996 making the estimates for PM10 far less precise than for the other parameters. The present analysis is based on a dataset including an additional year from 1994-1997.

Changes in FVC were assumed to be a surrogate for lung-function growth. FVC can be lowered either by a reflectoric inhibition of maximal inspiratory capacity or by destruction of the lung tissue due to inflammatory processes as described for $\mathrm{O}_{3}$ [29]. In this study, FVC growth was primarily affected by $\mathrm{NO}_{2}$ in winter and by $\mathrm{O}_{3}$ in both seasons.

Only a few studies dealing with lung-volume growth and particulate matter have been published. A recent study showed associations between ambient air pollutants (including PM2.5 and PM10) and poorer gain of FVC in children living in a polluted area of Krakow [30]. However, this study had some limitations, as it compared only two areas (city and suburb) with each other. Possible socioeconomic differences in two areas could never be fully determined in such studies, making it hard to attribute health effects to air pollution.

A recently published study investigated more than 3,000 schoolchildren living in Southern California [25]. Over a period of 4 yrs, measures for particulate matter (PM10, PM2.5, PM10-PM2.5) showed a negative association with lung-function growth. The difference of the annual growth rates between the most and the least polluted city for FVC and PM10, were $-0.58 \% \quad(95 \%$ CI $-1.14-0.02)$. Furthermore associations were found for $\mathrm{NO}_{2}(-0.53 \% ; 95 \% \mathrm{CI}$ $-1.01-0.05)$ and inorganic acid vapour $(-0.57 \%$; $95 \%$ CI -1.06--0.07). No significant associations were found for $\mathrm{FVC}$ growth and $\mathrm{O}_{3}$. One explanation as to why comparable results, to the aforementioned study, concerning PM10 were not found in this study is that there was little variation in the PM10 concentration across the cities (summer: $11.7-28.9 \mu \mathrm{g} \cdot \mathrm{m}^{-3}$; winter: $9.4-30.5 \mu \mathrm{g} \cdot \mathrm{m}^{-3}$ ). In the study by GaUdERman et $\mathrm{al}$. [25] PM10 concentrations varied substantially across the 12 communities observed. From the least to the most polluted community, PM10 concentrations varied by a factor of $4\left(51.5 \mu \mathrm{g} \cdot \mathrm{m}^{-3}\right.$ (annual average) difference) between the least and the most polluted community. The negative impact of $\mathrm{O}_{3}$ in the present study confirmed recently published data of the Austrian Lung and Air Study concerning $\mathrm{O}_{3}$ effects [26] on children's health, and are consistent with results from other studies [31, 32]. The LA study [25] found no significant association between $\mathrm{O}_{3}$ exposure and lung-function growth. The authors explained the findings by the modest range of $\mathrm{O}_{3}$ exposure in the 12 communities studied. Another reason could be different correlations of PM10 with other air pollutants in Austria and LA. For example $\mathrm{O}_{3}$ was less negatively correlated with $\mathrm{NO}_{2}$ and PM10 in LA (coefficient $\mathrm{NO}_{2}$ : -0.49, PM10: -0.32) than Austria (coefficient $\mathrm{NO}_{2}$ : -0.84 (winter), -0.63 (summer); PM10: -0.58 (winter), -0.43 (summer)). Cross-sectional studies like the 24-cities study [24] stress the longitudinal findings of an effect of $\mathrm{O}_{3}$ on lung-function parameters.

The growth of large airways, measured by FEV1 dpd, showed a negative effect for summer PM10 and winter $\mathrm{NO}_{2}$. Furthermore, $\mathrm{O}_{3}$ was negatively related to FEV1 independently of season. The results confirm observations by GAUDERMAN et al. [25] in LA. They observed a $-0.85 \%$ difference in annual growth of FEV1 between the most and the least polluted city $(95 \% \mathrm{CI}$ -1.28--0.1) for PM10. Previous calculations of the dataset between spring 1994 and autumn 1996 showed comparable results concerning $\mathrm{NO}_{2}$ and $\mathrm{O}_{3}$. Conversely, a negative impact of PM10 on the development of lung function could not be shown in these earlier analyses. One possible explanation for these differences is that the present analyses were based on the data of an additional year, making the observations more precise than the previous calculations.

The development of small airways (MEF25-75) was predominantly affected by summer PM10. A change of $10 \mu \mathrm{g} \cdot \mathrm{m}^{-3}$ PM10 was associated with a decrease of $0.9 \mathrm{~mL} \cdot \mathrm{s}^{-1} \cdot \mathrm{day}^{-1}$ that is about $164 \mathrm{~mL} \cdot \mathrm{s}^{-1}$ in one 
summer period. Although the $\mathrm{NO}_{2}$ effect in the summer lost significance when controlled for PM10, an additional effect, especially in the winter season, cannot be ruled out. These observations are also confirmed by the analyses of the LA study. GAUDERMAN et al. [25] found a negative effect both for PM10 and $\mathrm{NO}_{2}$ on the maximal midexpiratory flow that is comparable to the MEF25-75. The annual difference in growth between the least and the most polluted region was $-1.32 \%(95 \%$ CI $-2.43-0.2)$ for PM10 and $-1.08 \%$ (95\% CI -20.7-0.08) for $\mathrm{NO}_{2}$.

An important issue, which was raised in an editorial by TAGER [33], was the possible surrogate effect of air pollutants. As air pollution is usually a mixture of substances with unknown interactions and overlapping effects, it is scarcely possible to ascribe an association with respiratory-health indicators to a single pollutant. Thus, two-pollutant models were calculated to account for some of these concomitant effects. Nevertheless, the associations found for PM10, $\mathrm{NO}_{2}$ and $\mathrm{O}_{3}$ did not change to a significant extent suggesting, at the very least, a partial independent effect of these pollutants.

Results of epidemiological studies can be influenced by bias and confounding variables. In order to minimize observer-measurement variability, all the lung-function measurements, throughout the study period, were performed by the same two trained medical students. Data concerning the respiratory health of the children were not known to the research team at the beginning of the project. Furthermore, potential confounders like passive smoking, parental education or atopy were adjusted for in all the models.

In epidemiological studies dealing with the effect of air pollution on lung-function growth, the definition of exposure and outcome is crucial. The authors decided to calculate the interval for air-pollution exposure between two subsequent measurements of lung function, instead of a cumulative exposure for the following reasons. First, as the long-term effects were examined, a longer period of exposure had to be considered. Second, the assumption of a cumulative exposure needed a clear definition of a zero level, at which the children had not been exposed to pollutants. As the study was initiated at an age of $\sim 8 \mathrm{yrs}$, the children have to be regarded as being pre-exposed as they had already experienced $8 \mathrm{yrs}$ of air pollution before the start of the study. Third, the calculation of interval air-pollution exposure allowed for the adjustment of different seasonal aspects as discussed earlier.

Seasonal differences can at least partly be explained by different sources of air-pollutants. For example, in winter domestic fuel makes a larger contribution to total air pollution when compared to the summer. Furthermore different sources of air pollutants could lead to a different chemical composition of particulate matter. Finally, the children's behaviour could be different when comparing winter to summer, as they usually spend more time indoors during the cold season and are exposed to indoor pollutants (ETS etc.).

With regards the outcome (i.e. parameters of lung function) there are also two options available for calculating lung-function growth. The first is to perform measurements at the beginning and at the end of a study period. The second method, which was used by the authors, is to perform repeated lung-function tests and to calculate the respective lung-function growth between two subsequent measurement points, being aware that by short-term exposure more background "noise" is introduced into the data. The advantage of the first method is that the calculated effect estimate would be more stable as the scatter of the data points is minimal. But on the other hand, this method would lead to a severe reduction in data thus leading to a loss of precision. Furthermore declinations from the linear growth line could not have been accounted for. To investigate the first method the difference between the last (autumn 1997) and the first (autumn 1994) FEV1 was calculated, and the result divided by the number of days between the measurements (to get the FEV1 dpd) and regressed against the mean PM10 concentration adjusting for the same confounders as in the previous models. The result showed a parameter estimate of $-0.036(p=0.059)$ that was comparable to the summer effect found in the previous analysis $(\beta=-0.023 ; p=0.003)$ although weaker, as the winter effect had to be accounted for $(\beta=0.001 ; p=0.885)$.

To conclude, the present study provided further evidence for a long-term effect of particulate matter $<10 \mu \mathrm{m}$ in diameter on the development of pulmonary function in elementary schoolchildren. Early impairment of lung-function growth could lead to lower lung-function parameters in adulthood, predisposing to chronic pulmonary diseases [34].

\footnotetext{
Acknowledgements. The authors would like to thank N. Künzli (Institute of Social and Preventive Medicine of the University of Basel), for a thorough evaluation of the manuscript.
}

\section{References}

1. Pope CA III, Dockery DW, Spengler JD, Raizenne ME. Respiratory health and PM10 pollution. Am Rev Respir Dis 1991; 144: 668-674.

2. Hoek G, Brunekreef B. Acute effects of a winter air pollution episode on pulmonary function and respiratory symptoms of children. Arch Environ Health 1993; 48: $328-335$.

3. Hoek G, Brunekreef B. Effects of low level winter air pollution concentrations on respiratory health of Dutch children. Environ Res 1994; 64: 136-150.

4. Schwartz J, Dockery DW, Neas LM, et al. Acute effects of summer air pollution on respiratory symptom reporting in children. Am J Respir Crit Care Med 1994; 150: 1234-1242.

5. Braun-Fahrländer C, Vuille JC, Sennhauser FH, et al. Respiratory health and long-term exposure to air pollutants in Swiss schoolchildren. Am J Respir Crit Care Med 1997; 155: 1042-1049.

6. Ware JH, Ferris BG Jr, Dockery DW, Spengler JD, Stram DO, Speizer FE. Effects of ambient sulfur oxides and suspended particles on respiratory health of preadolescent children. Am Rev Respir Dis 1986; 133: 834-842. 
7. Horak F Jr, Studnicka M, Gartner C, et al. Der Einfluss von inhalierbaren Staubpartikeln (PM10) auf Lungenfunktion und respiratorische Symptome bei niederösterreichsichen Volksschulkindern. Wien Klin Wochensch. 2000; 112/3: 126-132.

8. Pope CA III. Respiratory disease associated with community air pollution and a steel mill, Utah Valley. Am J Public Health 1989; 79: 623-628.

9. Morgan G, Corbett S, Wlodarczyk J. Air pollution and hospital admissions in Sydney, Australia 1990 to 1994. Am J Public Health 1998; 88: 1761-1766.

10. Schwartz J, Morris R. Air Pollution and Hospital Admissions for Cardiovascular Disease in Detroit, Michigan. Am J Epidemiol 1995; 142: 23-35.

11. Schwartz J, Slater D, Larson TW, Pierson WE, Koenig JQ. Particulate air pollution and hospital emergency visits for asthma in Seattle. Am Rev Respir Dis 1993; 147: 826-831.

12. Ostro BD, Lipsett MJ, Wiener MB, Selner JC. Asthmatic response to airborne acid aerosols. A. J Public Health 1991; 81: 694-702.

13. Whittemore AS, Korn EL. Asthma and air pollution in the Los Angeles area. Am J Public Health 1980; 70: 687-696.

14. Roemer W, Hoek G, Brunekreef B. Effect of ambient winter air pollution on respiratory health of children with chronic respiratory symptoms. Am Rev Respir Dis 1993; 147: 118-124.

15. Ackermann-Liebrich U, Leuenberger P, Schwartz J, et al. Lung function and long-term exposure to air pollutants in Switzerland. Am J Respir Crit Care Med 1997; 155: 122-129.

16. Dockery DW, Ware JH, Ferris BG Jr, Speizer FE, Cook NR, Hermann SM. Change in pulmonary function in children associated with air pollution episodes. J Air Pollut Control Assoc 1982; 32: 937-942.

17. Schwartz J. Lung function and chronic exposure to air pollution: a cross-sectional analysis of NHANES II. Environ Res 1989; 50: 309-321.

18. Dockery DW, Pope A, Xu X, et al. An association between air pollution and mortality in six U.S. cities. N Engl J Med 1993; 329: 1753-1759.

19. Pope CA III, Thun M, Namboodiri M, et al. Particulate air pollution as a predictor of mortality in a prospective study of U.S. adults. Am J Respir Crit Care Med 1995; 151: 669-674.

20. Pope CA III, Dockery DW. Acute health effects of PM10-pollution on symptomatic and asymptomatic children. Am Rev Respir Dis 1992; 145: 1123-1128.
21. Studnicka M, Frischer $\mathrm{T}$, Meinert R, et al. Acidic particles and lung function in children. A summer camp study in the Austrian Alps. Am J Respir Crit Care Med 1995; 151: 423-430.

22. Roemer W, Clench AJ, Englert N, et al. Inhomogeneity in response to air pollution in European children (PEACE project). Occup Environ Med 1999; 56: 8692.

23. Dockery DW, Speizer FE, Stram O, Ware JH, Spengler JD, Ferris BG Jr. Effects of inhalable particles on respiratory health of children. Am Rev Respir Dis 1989; 139: 587-594.

24. Raizenne M, Neas LM, Damokosh AI, et al. Health effects of acid aerosols on North American Children: pulmonary function. Environ Health Persp 1996; 104: 506-514.

25. Gauderman VJ, McConnel $\mathrm{R}$, Gilliland $\mathrm{F}$, et al. Association between air pollution and lung function growth in Southern California children. Am J Respir Crit Care Med 2000; 162: 1383-1390.

26. Frischer T, Studnicka M, Gartner C, et al. Lung function growth and ambient ozone. A three years population study in school-children. Am J Respir Crit Care Med 1999; 160: 390-396.

27. Asher MI, Keil U, Anderson HR, et al. International study of asthma and allergies in childhood (ISAAC): rationale and methods. Eur Respir J 1995; 8: 483-491.

28. Liang KY, Zeger SL. Longitudinal data analysis using generalized linear models. Biometrika. 1986; 73: 13-22.

29. Committee of the Environmental and Occupational Health Assembly of the American Thoracic Society. Health effects of outdoor air pollution. Am J Respir Crit Care Med 1996; 153: 3-5.

30. Jedrychowski W, Flak E, Mróz E. The adverse effect of low levels of ambient air pollutants on lung function growth in preadolescent children. Environ Health Perspect 1999; 107: 669-674.

31. Stern BR, Raizenne ME, Burnett RT, Jones L, Kearney J, Franklin CA. Air pollution and respiratory health: exposure to sulfate and ozone in 10 Canadian rural communities. Environ Res 1994; 66: 125-142.

32. Schwarz J. Lung function and chronic exposure to air pollution: a cross sectional analysis of NHANESII. Environ Res 1998; 50: 309-321.

33. Tager I. Air pollution and lung function growth. Am J Respir Crit Care Med 1999; 160: 387-389.

34. Vestbo J, Prescott E. Update on the "Dutch hypothesis" for chronic respiratory disease. Thorax 1998; 53: Suppl. 2, S15-S19. 